\title{
Impact of Waterborne Copper on the Structure of Gills and Hepatopancreas and its Impact on the Content of Metallothionein in Juvenile Giant Freshwater Prawn Macrobrachium rosenbergii (Crustacea: Decapoda)
}

Na Li $\cdot$ Yunlong Zhao $\cdot$ Jian Yang

Published online: 17 March 2009

(C) Springer Science+Business Media, LLC 2009

Erratum to: Arch Environ Contam Toxicol 52(1):73-79

DOI 10.1007/s00244-005-0214-5

An incorrect version of Fig. 1 was printed in this paper. The corrected version is reprinted on the following page.

The online version of the original article can be found under doi:10.1007/s00244-005-0214-5.

N. Li · Y. Zhao

School of Life Science, East China Normal University,

Shanghai 200062, People's Republic of China

J. Yang $(\bowtie)$

Key Laboratory of Ecological Environment and Resources of Inland Fisheries, Freshwater Fisheries Research Center,

Chinese Academy of Fishery Sciences, Wuxi 214081,

People's Republic of China

e-mail: yangj@ori.u-tokyo.ac.jp 


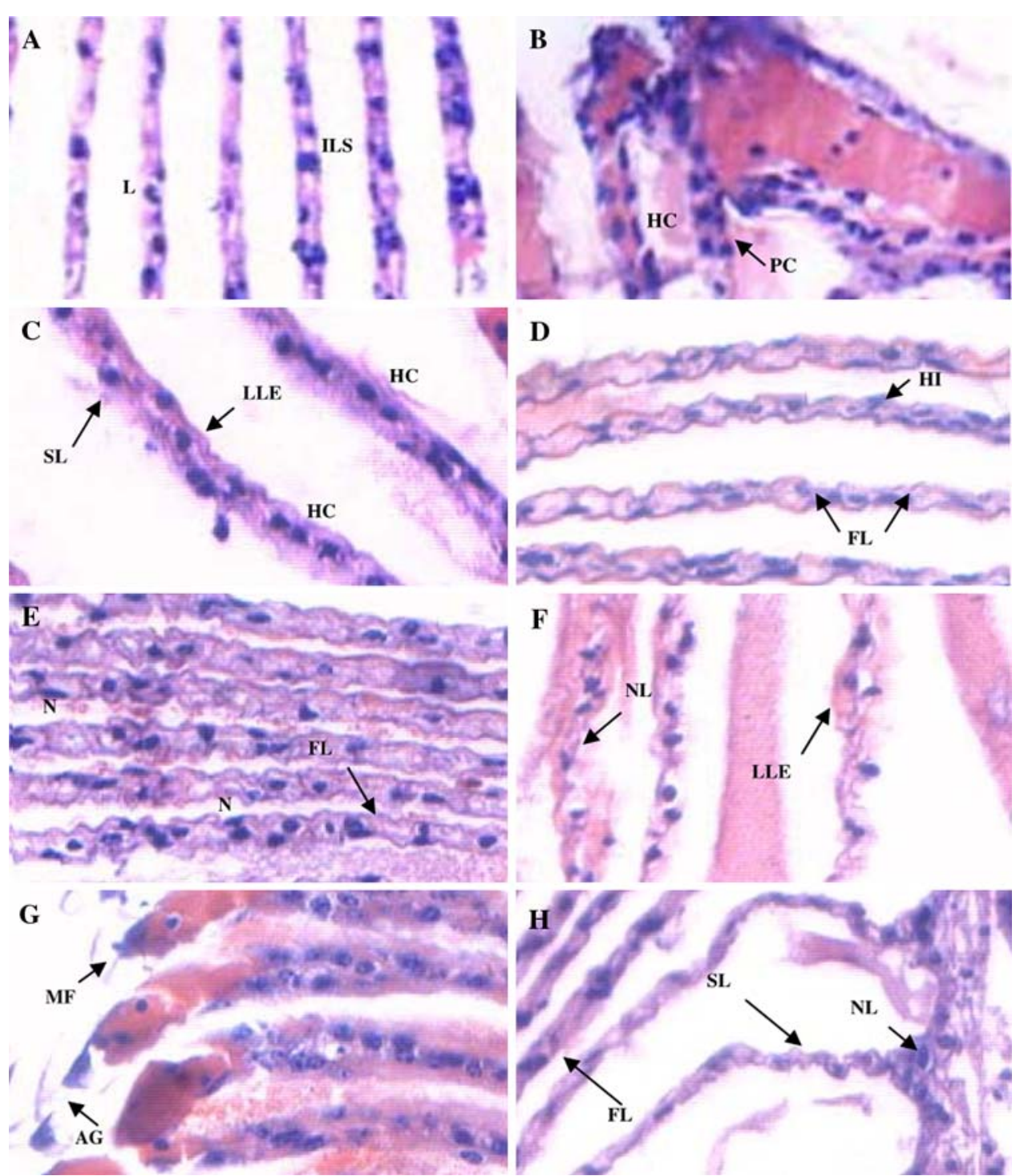

Fig. 1 Effects of waterborne copper on the microstructure of gills from juvenile Macrobrachium rosenbergii. a Typical organization of the gills (control). Gill lamellae (L) with uniform interlamellar space (ILS), $\times 200$; b Typical organization of the gills (control). Normal hemocoelic space with the optimum number of hemocytes (HC) and pillar cells $(\mathrm{PC})$ were found to extend into the lamellar sinus, $\times 400$; c Exposure to $0.01 \mathrm{mg} / \mathrm{L}$ copper. Swelling of gill lamellae (SL), lifting of lamellar epithelium (LLE) and the accumulation of hemocytes (HC) in the hemocoelic space of the gill lamellae, $\times 400$; d Exposure to $0.05 \mathrm{mg} / \mathrm{L}$ copper. Hemocytic infiltration (HI) in the hemocoelic space and fusion of gill lamellae (FL) in test prawns, $\times 400$; e Exposure to $0.1 \mathrm{mg} / \mathrm{L}$ copper. Narrower $(\mathrm{N})$ or obstructed hemolymph vessels and fusion of gill lamellae (FL) in test prawns, $\times 400$; f Exposure to $0.2 \mathrm{mg} / \mathrm{L}$ copper. Necrotic gill lamellae (NL) and lifting of lamellar epithelium (LLE) in test prawns, $\times 400$; g Exposure to $0.3 \mathrm{mg} / \mathrm{L}$ copper. Abnormal gill tips (AG) and malformation (MF) at the tips of the gills in test prawns, $\times 400$. h Exposure to $0.4 \mathrm{mg} / \mathrm{L}$ copper. Fusion of gill lamellae (FL), swelling of gill lamellae (SL), and necrotic gill lamellae (NL) in test prawns, $\times 200$ 